\title{
Combined Effects of Constitutional and Organopathic Homeopathic Medicines for Better Improvement of Benign Prostatic Hyperplasia Cases
}

Paital $\mathrm{B}^{1}$, Hati $\mathrm{AK}^{2}$, Nanda $\mathrm{LK}^{2}$, Mishra $\mathrm{AK}^{2}$ and Nayak $\mathrm{C}^{3}$

${ }^{1}$ Deptartment of Zoology, Orissa University of Agriculture and Technology, Bhubaneswar, India

${ }^{2}$ Dr. Abhin Chandra Homoeopathic Medical College \& Hospital

${ }^{3}$ Homoeopathy University, Saipura, Sanganer, Jaipur-302029, Rajasthan, India.
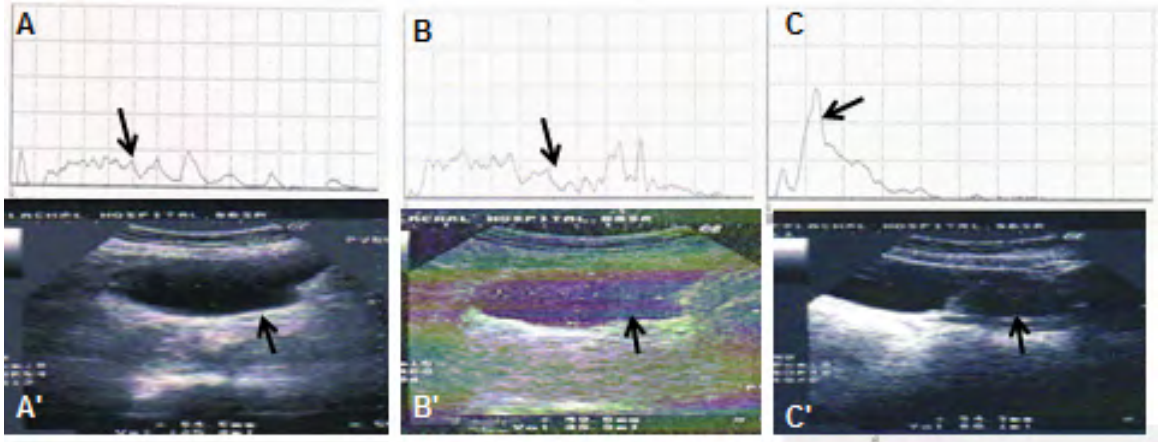

D
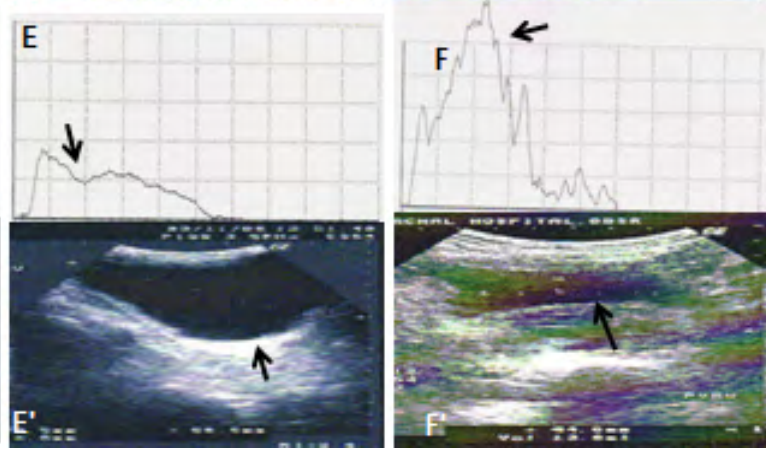

Figure 1: The black arrow shows the changes in RUV and UFM before and after treatment in patients.

\section{Clinical Image}

\section{Genesis of the Problem}

Benign prostatic hyperplasia (BPH) is a histological diagnosis associated with unregulated proliferation of connective tissue, smooth muscle and glandular epithelium. BPH may compress the urethra and result in bladder outlet obstruction (BOO). $\mathrm{BPH}$ and $\mathrm{BOO}$ have a significant impact on the health of older men and health-care costs. Voiding symptoms have often been attributed to the physical presence of $\mathrm{BOO}[1,2]$.The homoeopathic literature states that a number of constitutional and organopathic medicines are effective in treating patients suffering from BPH. However, the systematic studies on it are too scanty as evidences and the claims are not well-documented [1,2]. So many arguments are done on this issue of homeopathic medicines [3]. Hence, the objective of the present study was undertaken to evaluate the effects of either Constitutional medicines (CM) or Organopathic medicines (OM) prescribed alone or Constitutional medicines followed by Organopathic medicines (BCOM) to the patients suffering from $\mathrm{BPH}$.

\section{Materials and Methods}

The study was conducted at the Dr. A.C. Homoeopathic Medical College \& Hospital, Bhubaneswar, India from April 2005 to

*Corresponding author: Dr. Biswaranjan Paital, Department of Zoology, Orissa University of Agriculture and Technology, College of Basic Science and Humanities, Bhubaneswar-751003, Odisha, India, Tel: +91-9337413232; E-mail: biswaranjanpaital@gmail.com

Citation: Paital B, Hati AK, Nayak C, Mishra AK, Nanda LK (2017) Combined Effects of Constitutional and Organopathic Homeopathic Medicines for Better Improvement of Benign Prostatic Hyperplasia Cases. Int J Clin Med Imaging 4: 574. doi:10.4172/2376-0249.1000574 
April 2008 with financial support of Central Council for Research in Homoeopathy, Govt. of India. Patients were diagnosed as suffering from $\mathrm{BPH}$ on the basis of obstructive symptoms, digital rectal characteristics, ultrasonography (for prostate size and residual urine volume, RUV) and uroflowmetry (UFM). All total 180 patients (60 per group) completed treatment and were included in final analysis. Patients were prescribed with constitutional medicines such as Thuja, Conium, Sulph, Lycopodium, Iodium, Pulsatilla, Merc. sol., Bar. carb., Nat.mur., Lyssin, Tuberculinum, Calc. carb. Lachesis, Gelsemium, Lyssin, Tuberculinum, Carcinosin and Staphysagria or organopathic medicines such as Sabal ser., Hydrangea., Chimaphilla., Solidago, Senecio., Triticum., Ferr. pic. and Pic. acid as per their symptoms. Outcome assessment was done on the basis of IPSS, USG and UFM findings, however, clinical images of only ultrasound for RUV and UFM for urine flow rate are presented in the current article.

\section{Results and Discussion}

In the representative figures of thee patients remarkable improvement were observed in three groups with homeopathic medicines. Figure A, C and E, represent UFM of the patients in OM, CM and BCOM group, respectively before treatment. Figure B, D and F, represent UFM of the above corresponding patients in OM, CM and BCOM group, respectively after treatment. Similarly, Figure A', C' and E', represent UFM of the patients in OM, CM and BCOM group, respectively before treatment. Figure B', D' and F', represent UFM of the above corresponding patients in OM, CM and BCOM group, respectively, after treatment. In all cases, although substantial increase in flow rate and decrease in RUV were observed, the results were more significant in BCOM group in comparison to the other two groups. Therefore, both OM and CM are advised to treat the patients with $\mathrm{BPH}$ cases rather than with only OM or CM.

\section{References}

1. Hati AK, Paital B, Naik KN, Mishra AK, Chainy GBN, et al. (2012) Constitutional, organopathic and combined homeopathic treatment of benign prostatic hypertrophy: a clinical trial. Homeopathy 101: 217-223.

2. Nix JW, Carson CC (2007) Medical management of benign prostatic hypertrophy. Can J Urol 1: 53 e57.

3. Paital B, Hati AK, Naik KN, Mishra AK, Nanda LK, et al. (2014) Re: Editorial Comment on Constitutional, Organopathic and Combined Homeopathic Treatment of Begin Prostatic Hypertrophy: A Clinical Trial. J Urol 193: 1-2.

4. Mantovani F (2010) Serenoa repens in benign prostatic hypertrophy: analysis of 2 Italian studies. Minerva Urol Nefrol $62(4)$ : 335 e340.

5. Murphy RND (1998) Homoeopathic medical repertory. New Delhi, India: B Jain Publishers (P) Ltd. 